\title{
Televisión digital y programación: de la televisión de siempre a la televisión de pago y multicanal
}

\author{
José Luis Ibáñez Serna \\ Profesor titular en la Facultad de CC. Sociales y de la Comunicación de \\ la Universidad del País Vasco. \\ Emilio Fernández Peña \\ Departamento de Educación y Universidades del Gobierno Vasco.
}

El presente artículo analiza la evolución de la programación en las televisiones en España desde sus inicios a mediados de los años cincuenta con una televisión pública y en blanco y negro hasta la televisión digital multicanal de pago. A pesar de los años transcurridos y de los avances tecnológicos que se han producido la programación no ha variado sustancialmente. Lo que sí ha cambiado ha sido la cantidad de la oferta y la presentación al público; ahora por áreas temáticas.

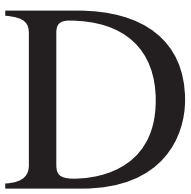

esde la puesta en marcha de la primera televisión en España (TVE) hasta las nuevas televisiones digitales han transcurrido poco más de cuarenta años. En este periodo el modelo televisivo español se ha modificado de una manera ostensible. Donde anteayer había una televisión pública, única y gratuita; ayer un conjunto de televisiones públicas y privadas gratuitas a excepción de Canal Plus; hoy trata de abrirse paso la nueva televisión privada multicanal y de pago con incrustaciones públicas en alguno de los casos.

\section{Televisión española. Los primeros años}

Televisión Española inaugura de manera oficial sus emisiones el 28 de octubre de 1956. Así, al final de la década de los cincuenta, España tendrá una televisión en blanco y negro, analógica, única, pública, generalista y gratuita. Llegaba hasta los receptores por ondas electromagnéticas (VHF) y emitía informativos, teleseries, cine, teatro, programas de variedades, espacios infantiles y diversas retransmisiones: fútbol, toros y otras.

Desde 1967, emite de forma regular la Segunda Cadena o UHF, si bien no llega a todos los lugares de España. La UHF programa únicamente tres 
horas diarias entre las 20.30 y las 23.45. Se trata de una programación cultural que podría calificarse, salvando las distancias, de precursora de los actuales canales temáticos.

\section{Las televisiones autonómicas. Euskal telebista}

Entre los años 70 y los 90 la tecnología y el panorama audiovisual evolucionan significativamente. En 1976 hay en España 8.200.000 televisores, de los que 800.000 están preparados para emitir en color ${ }^{1}$. A principios de los 90, la televisión es en color, analógica, pública o privada, generalista o temática, gratuita o de pago. Llega a los receptores de los hogares por ondas electromagnéticas, por satélite $\mathrm{y}$, en menor medida, por cable.

En los años 80 surgen las televisiones autonómicas. La primera televisión autonómica, Euskal Telebista, inicia sus emisiones de manera experimental en los primeros meses de 1983.

Un estudio ${ }^{2}$ realizado sobre las características de su programación concluía:

1) El gran peso que el cine y las series tenían en la programación de ETB1. Más del 33\% de las 367 horas y media semanales de programación estaba dedicado a esta categoría.

2) La gran importancia de los programas deportivos. Un $20,68 \%$ del total.

3) Pese a las intenciones fundacionales de EITB, llamaba poderosamente la atención el escaso porcentaje que alcanzaban los programas de carácter cultural en la parrilla de programación de ETB1 (6\%).

4) Los informativos constituían el $13 \%$ de la programación y aquí se producía la única excepción en el uso continuado del euskera: el informativo diario Teleberri se emitía en castellano a las 14’30 de la tarde.

5) La publicidad apenas superaba el $2 \%$ y ello por falta de contratación. No porque la política del ente fuera en una dirección no comercial.

6) Más de la mitad de la programación, el 63\%, correspondía a producciones ajenas. Del total de la producción ajena, casi la mitad pertenecía a países europeos, en tanto que la otra mitad procedía de Norteamérica (Estados Unidos y Canadá). El resto, un 3\%, eran producciones latinoamericanas, básicamente, las series conocidas popularmente como culebrones.

2 IBAÑEZ, J.L. y MARIN, F. "La estructura de la programación de ETB-ETB 1: la circulación de los programas de televisión. La programación cultural”. Kobie (Serie Bellas Artes). Diputación de Vizcaya, nº 5. 1988. pp. 7 27. 


\section{Las televisiones privadas}

A principios de los 90, concretamente en los meses de enero y marzo inician sus emisiones las primeras televisiones privadas gratuitas en España. Son Antena 3 (25.1.1990) y Tele 5 (3.3.1990). Por su parte, Canal Plus, la primera televisión de pago, llega a las pantallas con carácter oficial el martes 4 de septiembre de ese mismo año.

No se podía hablar de la Televisión privada en España sin tener en cuenta los orígenes y el desarrollo de la televisión en EEUU y en Europa, así como los modelos que adoptó.

La Televisión se desarrolla en los Estados Unidos de América en forma de actividad privada y comercial, financiada por la publicidad y con una programación orientada fundamentalmente al entretenimiento y a la diversión de los espectadores, más que a su desarrollo cultural.

La financiación de las emisiones por agencias de publicidad que desean atraer grandes audiencias para sus mensajes, condujo a un modelo basado en el sensacionalismo y en la espectacularidad. Para paliar el comercialismo, la F.C.C. (Federal Communications Commision) impuso en 1961 la transmisión de unos tiempos mínimos dedicados a noticias y a asuntos de interés público.

A diferencia de Estados Unidos, la Televisión en Europa se configura, inicialmente, como un servicio público debido a una serie de razones entre las que destacan:

- la tradición de la empresa pública radiofónica dominante en Europa y que servirá como modelo para el desarrollo del sistema televisivo.

- la coincidencia de planteamientos entre la derecha y la izquierda políticas que consideraban a la televisión como un medio demasiado influyente en la sociedad para dejarlo en manos de las empresas privadas.

Sin embargo, pese a estar estructuradas como entes públicos, las televisiones europeas no serán capaces de evitar totalmente el modelo americano en su programación.

Esta tendencia se intentaría corregir con la creación de canales UHF dirigidos a públicos con un nivel cultural más exigente y selectivo. Si bien la televisión pública y la privada coexisten en Inglaterra desde 1955, el gran debate sobre televisión pública/televisión privada no se anima en Europa hasta los años setenta.

Esta situación lleva a preguntarse por la viabilidad de reunir en un sólo modelo las ventajas de la televisión pública y las de la privada: la indepen- 
dencia de los intereses comerciales y la vocación de servicio a la sociedad de la pública y la pretendida creatividad e innovación de la privada.

La respuesta -un sistema mixto en el que compitan públicas y privadas podría contribuir a paliar defectos y sumar cualidades de unas y otrasparece ingenua cuando menos.

La coexistencia de la televisión pública y privada no hace sino homogeneizar la oferta de la programación y empuja a la televisión pública a entrar en la lógica de mercado, anteponiendo la comercialidad a la calidad. Y es que no puede ser de otra manera.

Cuando la actividad televisiva obedece a criterios económicos y comerciales y se regula por las leyes del mercado, el estado se ve incapacitado para orientar el sistema televisivo hacia fines de interés general, sean éstos de naturaleza económica, política o socio-cultural.

\section{La televisión privada en España}

La historia de la televisión en España hasta principios de los ochenta es la historia de TVE. Hasta entonces el modelo de televisión existente es consecuencia de un complejo ordenamiento jurídico que, al igual que había ocurrido en otros países, se asienta en la normativa del modelo radiofónico.

Con todo, pese a que las autoridades optan en su momento por un modelo público de televisión, las diferencias del caso español con los países de Europa occidental fueron notables. Así, no se recurrió al canon por tenencia de aparato para su financiación y TVE fue en su momento una de las pocas televisiones públicas europeas cuya financiación procedía casi exclusivamente de la publicidad.

Del primer estudio global realizado sobre la programación de todas las televisiones españolas, incluidas las privadas -excepto Canal Plus ${ }^{3}$ - se obtienen las siguientes conclusiones:

Los programas de entretenimiento alcanzaban el $78 \%$ en Tele 5 por arriba y el 55\% en TVE1 por abajo. Entre las televisiones autonómicas, Telemadrid alcanzaba casi el $69 \%$ frente al $54 \%$ de TV3.

Los informativos ocupaban el $27 \%$ en TVE1. TVG parecía la menos interesada de las televisiones públicas en esta categoría, con un $15 \%$. Por

\footnotetext{
IBAÑEZ, J. L. "Estado actual de la programación en las televisiones públicas y privadas" en VV.AA Las radiotelevisiones en el espacio europeo. Ente Público RTVV. Valencia, 1990. pp.181-218. Este estudio que dio lugar al artículo fue dirigido por José Luis Ibañez y participaron en él: Fernando García, Iñaki Izquierdo, Alfredo Joaquín, Begoña Luzuriaga, Arantza Sáez de Asteasu, Encarnación Sáinz y Javier de la Fuente, todos ellos exalumnos de la Facultad de CC. Sociales y de la Comunicación de la UPV.
} 
debajo de la televisión privada Antena 3, aunque por encima de Tele 5 $(2,44 \%)$.

La programación cultural ocupaba el mayor porcentaje en Canal 33, con un $14 \%$, contra el $4 \%$ de TVE1 entre las televisiones públicas.

En términos generales, existía una gran homogeneización en la programación que corresponde con una filosofía competitiva de todos contra todos.

Si existía un modelo de televisión pública autonómica, éste había que buscarlo fuera de los criterios de programación y contenidos.

\section{Canal Plus}

Canal + , que ya cuenta con 1,5 millones de abonados, fue la primera televisión de pago en España. Su aparición instaura una nueva cultura televisiva que es la de pagar por ver la televisión. La transición hacia la televisión multicanal de pago se había iniciado.

Juan Luis Cebrián había declarado ya en noviembre de 1989 a la revista Class que Canal Plus sería un gran club de entretenimientos (cine y deporte) en la parte codificada y en la no codificada emitiría informativos de calidad y programas de ocio similares a otras televisiones.

El primer canal de pago español no ha variado en gran medida su programación desde sus inicios. Un 59,9 \% de sus contenidos los dedica a ficción, un 16,2 a deportes y un 8,2 a programas culturales ${ }^{4}$. Los abonados a Canal + expusieron las razones de su suscripción en una encuesta realizada por la cadena de televisión. El 34,5 \% reconocía que se había abonado por el cine, el $31 \%$ por el fútbol, el 10,4\% por "la oferta diferente y de calidad", el 9,8\% por el deporte en general, el 3,5 por ausencia de publicidad, el 2,6 por la demanda familiar y el 1,9 por la programación taurina 5 .

\section{La televisión por cable}

Como señala Piaget ${ }^{6}$ la televisión por cable no procede de un descubrimiento científico ni de una nueva tecnología, sino más bien del encuentro fortuito del sistema de la transmisión por hilo con la televisión.

A partir de 1985 surgen en el sur y levante peninsular los llamados videos comunitarios ante la escasez de una oferta de ficción en la única

\footnotetext{
ALVAREZ MONZONCILLO, J.M Nuevas formas de consumo audiovisual: el caso hegemónico de la televisión de pago. Tesis Doctoral, Madrid, 1996, p. 357.

5 Ibídem, p. 365 y 366

6 PIAGET, Henry. La Televisión por cable empieza mañana. Fundesco-Editorial Tecnos. Madrid. 1985, p. 21
} 
Televisión digital y programación: de la televisión de siempre...

televisión publica. Si a esto se añaden las dificultados de recepción en algunos lugares de la geografía peninsular se entenderá el desarrollo, siquiera incipiente, del cable.

Algunos videos comunitarios se transforman en modestas empresas de televisión por cable al mejorar sus infraestructuras, ampliar su oferta y el número de hogares a los que llegan. Su programación se restringe a la reemisión de las cadenas nacionales y autonómicas herzianas junto con algunas recibidas vía satélite en su mayoría de otros países y en otros idiomas y en muchos casos también un canal local.

Otros operadores hasta un total de 27 constituyeron la denominada Asociación de Empresas de Servicios Distribuidos por Cable, AESDICA y sirven televisión por cable a 80.000 hogares. Estos operadores se diferencian de los primeros en sus mejores infraestructuras y en que pretenden ofrecer una mejor programación. Además del canal local propio emiten las televisiones por aire, las de satélite gratuitas y uno o varios paquetes adquiridos a las productoras y empaquetadoras, caso de Cableantena o Multicanal TPS (Canales de cine, infantiles, de documentales o de música, todos ellos en español). Es aquí donde radica la novedad respecto a los ya clásicos videos comunitarios reconvertidos en televisiones por cable. Su intención de satisfacer los derechos que conlleva la normativa de propiedad intelectual es una característica que los dota si cabe de mayor entidad.

Las grandes corporaciones se crean a partir 1992 ante el anuncio de que la ley se aprobaría de modo inminente. Sus accionistas son bancos, cajas y empresas eléctricas, principalmente. Son precisamente estas empresas las que se están haciendo, vía concurso, con el mercado ${ }^{7}$.

Junto a ellas Telefónica podrá operar en todas las demarcaciones 16 meses después de que se hayan resuelto los concursos. Si se tiene en cuenta que Telefónica es la máxima accionista de Vía Digital parece razonable pensar que los contenidos que transmita por cable serán básicamente los mismos que ofrece esa plataforma.

En diciembre de 1995 se aprueba la ley de Telecomunicaciones por Cable que regula no sólo los servicios de televisión multicanal que pueden

\footnotetext{
Cable i Televisió de Catalunya ha ganado el concurso en las tres demarcaciones de Catalunya; Redes de Telecomunicaciones de Castilla y Loen (Retecal) el de la demarcación única de Castilla y León; Cádiz Cable y Televisión, en la capital gaditana; Mallorquina de Cable en Palma de Mallorca; Valenciana de Cable en la ciudad de Valencia; en Oviedo, Gijón y Avilés, la Sociedad Promotora de las Telecomunicaciones en Asturias; Supercable Sevilla, en Sevilla ciudad; Teleaxarquía en Vélez-Málaga; en Murcia, Murcia de Cable y en Albacete, Albacete Sistemas de Cable. El País, 15 de febrero de 1998, Negocios, p. 3.
} 
transmitir los operadores, sino que se extiende a la telefonía y los servicios telemáticos que desde enero de 1998 pueden ofertar los cableoperadores. Atrás habían quedado seis anteproyectos de ley.

En 1996 se habían registrado 802 operadores que ofrecían servicios de televisión por cable a 420.000 abonados $^{8}$.

Hasta 1994 los contenidos audiovisuales temáticos en castellano eran muy escasos. A partir de octubre de 1994 se crea el paquete de programación en español TPS, más tarde se ofrece a los operadores TNT\&Cartoon Network con parte del audio en español y posteriormente surge Cableantena. Todos estos paquetes de programación ofrecen canales especializados en cine, series de televisión, contenidos para niños, documentales, o canales musicales. Los operadores de cable distribuían a sus abonados una oferta temática exclusiva. Con esta nueva oferta el cable español pasa de ofrecer películas de video, re-emitir canales por satélite sin costo alguno o de ser simplemente un modo de mejorar la recepción de las cadenas a convertirse en una fuente de programación diferenciada, una televisión no sólo de pago, sino temática.

\section{La televisión digital}

La televisión digital por satélite surge en 1994 en EE.UU, un país en el que el cable llegaba ya a 59.689.070 de hogares ${ }^{9}$. El desarrollo de la televisión digital se materializa gracias a la tecnología que posibilita la compresión digital, lo que permite multiplicar por siete o más los canales que se podían transmitir por un sólo transpondedor de satélite. Se debe tener en cuenta además que en el caso estadounidense existía un desarrollo importante de la televisión multicanal propiciada por el cable. El mercado proporcionaba una programación más que suficiente. Los canales digitales sólo tenían que adquirirla.

En España el grupo Prisa lanza los servicios de televisión digital por satélite con Canal Satélite Digital (CSD) el 31 de diciembre de 1997. En marzo de ese año la televisión digital por satélite inaugura los servicios de

\footnotetext{
8 FERnÁndeZ BEAUMONT, José. El País, 28 de mayo de 1996, p. 30. Según datos aportados por la Secretaría General de Telecomunicaciones fueron 802 los operadores que tras la aprobación de la ley solicitaron una licencia para seguir operando hasta diciembre de 1998. Para ello debían demostrar que en el momento de aprobarse la ley operaban televisión por cable. Tras inspecciones y solicitudes de información se concedieron las licencias de forma provisional.

9 Estimaciones de Nielsen Co. y publicadas en Cable television developments. Fall 1994. National Cable Television Association. Washinton. 1994 p. 1A.
} 
pago por visión. El 30 de septiembre de ese mismo año comienza sus emisiones Vía Digital.

El satélite hasta la aparición de la televisión digital alimentaba las cabeceras de los operadores del cable. Para aquellos usuarios que disponían de parabólica era también un canal de acceso a otros canales televisivos. La televisión digital hace del satélite una fuente de transmisión al hogar de una televisión multicanal y temática.

Esta nueva televisión supone una ruptura del concepto clásico de parrilla de programación siempre identificado con la televisión generalista.

Para el ex-director de la CBS, Gene Jankowski ${ }^{10}$ existen dos dinámicas en el mundo de la comunicación: la agregación de audiencias que identifica con aquellos productos de las industrias culturales (libros, discos o películas) que interesan a la mayor parte del público y la disgregación de audiencias que tiene que ver con los gustos de pequeñas audiencias por cuestiones especializadas. Según Jankowski esas dos dinámicas sirven a dos necesidades diferentes: la necesidad de pertenencia a un grupo social y la necesidad de ser individual y matiza que no son competitivas, sino complementarias.

\section{La televisión digital en España. Programación}

La oferta de la televisión digital está estructurada de la siguiente manera:

Un paquete básico en el que se incluyen algunos canales generalistas como los autonómicos, emisiones en otras lenguas (NBC Europe, Télévision internationale) y canales temáticos: infantiles, documentales, cinematográficos, informativos y otros.

Los contenidos de este paquete básico tienen un bajo costo para el operador, ya que en muchos casos son canales por satélite en abierto. En el caso de las plataformas digitales españolas muchos de estos canales son creación de las propias plataformas, puesto que apenas existían precedentes en el mercado de la televisión multicanal. Los operadores de satélite incluyen canales que propician la captación de nuevos abonados y el mantenimiento de los antiguos.

Para acceder a otros canales no incluidos en la oferta básica el abonado debe pagar una cantidad adicional. Es el caso de algunos canales cinematográficos.

${ }^{10}$ BALDWIN, T. \& MCVOY, S. Cable Communication. Prentice Hall, Inc. New Jersey. 1988. Second Edition, p. 6 . 
Existen además canales a la carta que se contratan individualmente y van dirigidos a públicos más restringidos (Canal Mundovisión para ciegos y sordos, Canal C: con telecarga o Muzzik).

En un principio el cine y fútbol eran los motivos que aducían los abonados a Canal Plus para suscribirse a la primera televisión de pago española. Curiosamente son estas categorías de programas los contenidos más contratados en el sistema de pago por visión (pay per view). En la nueva televisión multicanal se cobra más por acceder antes a un determinado tipo de programas. El proceso de estreno de las películas es el siguiente: primero pago por visión, después canales de pago (Canal Plus) y más tarde en los canales generalistas o en los paquetes básicos.

\section{Transición de la TV y programación publicitaria.}

Ninguna de las plataformas habla de publicidad y si lo hacen es para negarla. No en balde la televisión digital está financiada con el dinero de sus abonados.

No parece que las grandes marcas vayan a renunciar a difundir sus productos precisamente a las capas de población de mayor poder adquisitivo, es decir, al sector de la población que más fácilmente puede acceder a la televisión digital. Tampoco parece que las grandes marcas vayan a renunciar a unos públicos que las propias plataformas pueden ofrecer ya segmentado en función de sus gustos y preferencias audiovisuales.

Las fórmulas pueden ser varias, pero el patrocinio es seguramente la más adecuada y también la más sencilla.

Algunos de los canales que se anuncian bajo el nombre de Teletienda como servicios no son sino programación publicitaria. Un mercado que las grandes empresas de distribución no pueden dejar al margen.

Las agencias publicitarias en este momento tienen un gran reto: realizar la transición de la televisión generalista a la televisión digital con el mínimo coste posible, y eso requiere dedicar muchos recursos a la investigación.

\section{Consideraciones finales}

Si convenimos, cuarenta años después de la primera televisión pública española y ocho años después de la implantación de las televisiones privadas, que la televisión deriva hacia el negocio total, ¿qué será de la televisión pública generalista?. 
Hace unos meses parecía razonable pensar que si algún sentido iba a tener la televisión pública española en los próximos años, ese debía ser erigirse en elemento corrector de las diferencias sociales en el acceso a lo audiovisual con una programación de calidad.

La incorporación de Televisión Española a una de las plataformas, al igual que el resto de las televisiones autonómicas, puede ser el definitivo adiós a esa esperanza. Entre otras cosas porque las pérdidas de los entes públicos de televisión se cuentan ya por miles de millones.

La segunda gran oportunidad de la televisión pública generalista puede estar pasando a la historia. La primera fue con la llegada de las televisiones privadas y no supo aprovecharla. Se dejó llevar por el mercado y el mercado se quedó con ella.

La historia de la televisión es sobretodo la historia de su programación. La evolución tecnológica que ha influido de manera fundamental en el aumento del número de canales apenas ha influido en los contenidos esenciales de los programas. De hecho no son tantas las diferencias -excluidas las propias del desarrollo tecnológico- entre los programas emitidos en sus orígenes por Televisión Española y los que emite hoy cualquier televisión multicanal. Otra cosa sería considerar la abundancia de los programas.

La revitalización de los viejos programas (películas, series, documentales) es una de las consecuencias de la nueva televisión. Aquellos programas que las televisiones consideraban caducados adquieren un nuevo valor en el mundo de la televisión multicanal.

Algunos de los accionistas de la televisión digital por satélite española (TVE, Televisa o las autonómicas) producen miles de horas anuales de ficción, de informativos y de documentales.

Una parte de la programación de los canales que ambas plataformas emiten son de producción propia, otros son canales importados que en algunos casos se doblan y en otros se mantienen en el idioma original. Esta vocación de diversificación vertical hacia la producción o empaquetado de contenidos audiovisuales es propia de las plataformas digitales.

En cuanto al cable, es preciso señalar que el operador es, sobre todo, una empresa de infraestructuras. Según estudios recientes su principal fuente de ingresos estará en el teléfono ${ }^{11}$. Se puede hablar entonces de la televisión

\footnotetext{
${ }^{11}$ El Teléfono reportará un $51 \%$ de los ingresos y la televisión un $29 \%$ y los servicios de valor añadido un 20 \%. La Nueva España, 2 de noviembre de 1997 , p. II Revista.
} 
por cable como uno de los servicios que ofrecen los operadores de telecomunicaciones: un servicio de transmisión de programas de televisión básicamente, si bien cuenta con algunos intereses todavía muy limitados en el empaquetamiento y producción de contenidos.

Está por ver hasta qué punto la proliferación de las nuevas televisiones va a fomentar el desarrollo de la industria audiovisual española a gran escala: por un lado recurren al empaquetamiento de viejos contenidos; por otro se convierten en distribuidoras de los cientos de miles de horas de programas realizados y almacenados por la industria audiovisual estadounidense que debe dar salida a su producción.

La tendencia a no producir en consonancia al número de horas que se emite se había iniciado ya en los años ochenta en la televisión generalista. En esa época mientras los presupuestos de los canales de televisión se habían multiplicado por seis, las horas de emisión lo habían hecho por más de doce $^{12}$, una tendencia que probablemente se acentúe.

En la nueva televisión los programas de cada canal son clasificables en función de un tema central que la mayoría de las veces se manifiesta en diversos enfoques y géneros televisivos. Así en un canal sobre historia tienen cabida documentales sobre historia, películas y series históricas o un programa de entrevistas a historiadores.

El surgimiento de la televisión digital por satélite introduce por primera vez la competencia en la televisión de pago española monopolizada hasta entonces por Canal Plus. La llegada al mercado de Vía Digital beneficia a los abonados de Canal Plus que pueden suscribirse a CSD a un precio más ventajoso. Esta medida facilita el pase de los abonados de Canal Plus hacia el formato digital ${ }^{13}$. Las emisiones de Canal Plus convencional dan origen a tres canales digitales que se emiten en CSD. La transición de los espectadores a la televisión digital es una realidad.

Por lo que respecta a la programación publicitaria los canales temáticos son la coartada perfecta para una publicidad selectiva y perfectamente orientada al consumidor de esos canales.

\footnotetext{
12 ALVAREZ MONZONCILLO, J.M e IWENS J. L. El futuro del audiovisual en España: las transformaciones ante el marco europeo. Fundesco. Madrid. 1992, p. 29

${ }^{13}$ CSD ofrecía la posibilidad de recibir Canal Plus digital y el paquete básico por mil pesetas más de lo que cuesta el abono al primer canal de pago español, una oferta que se extiende hasta el 31 de agosto de 1998.
} 